\section{Uses of Allopurinol}

SIR,-With reference to your excellent leading article (23 October, p. 185), I would raise two points.

Having followed up a series of gouty patients for 20 years, first on uricosurics and then on allopurinol, I have no doubt in stating that the urinary complications while using the uricosuric drugs make allopurinol the preferable method of treatment in any case where it is decided to start long-term treatment. Secondly, from a follow-up of 50 cases, now for over five years, ${ }^{1}$ the dangers of long-term treatment seem to be minimal. Moreover, the return to statu quo on gradually ceasing treatment with allopurinol in the least severe cases is much less rapid than on discontinuing the uricosuric agents.-I am, etc.,

G. D. KERSLEY

Royal National Hospital for Rheumatic Diseases, Bath

1 Kersley, G. D., Annals of the Rheumatic Diseases, 1970, 29, 89.

\section{The New F.F.R.}

SIR,-Since the publication of the document "Training in Radiology and Examination for the Fellowship," which was accepted by the Annual Meeting of the Faculty of Radiologists in June 1971, a great deal of discussion and consultation has taken place. Many written and verbal comments have been received, and this includes a number of letters which have appeared in the British Medical Fournal.

In answer to Dr. F. Pygott's letter (28 August, p. 533) one specific point needs immediate qualification. The Faculty has no intention whatsoever "to phase out the value of the present Conjoint diploma (D.M.R.D. and D.M.R.T.)." This also applies to diplomas given by the Universities of Liverpool, Edinburgh, and Aberdeen. The Faculty cannot interfere in any way with the contents and examination structure of diplomas of other examination bodies.

Consultations and discussions are at present proceeding with the Conjoint Board and the universities how their qualifications can best be related to the new Fellowship examination structure. In the near future a letter will be sent to each Member and Fellow of the Faculty of Radiologists explaining the present position and bringing them up to date with new developments. It is hoped that this letter will answer some of the questions posed in your correspondence column and should dispel some of the anxieties expressed. -I am, etc.,

\section{R. E. STEINER}

London W.C.2 Warden of the Fellowship Board,
Faculty of Radiologists

\section{Misuse of Drugs Act 1971}

SIR,-I should like to make two comments on the critique by your legal correspondent of the Misuse of Drugs Act 1971 (2 October p. 60). He says that Section 28 of the Act "provides a general defence under the Act by reason of which an accused is entitled to be acquitted if he proves that he neither delivered nor suspected nor had reason to suspect that the substance or product in question was the particular controlled drug alleged'."

What purports to be a quotation from Section 28 is not a quotation from that or any other section of the Act. And Section 28 does not provide a general defence under the Act but a defence only in respect of certain named sections, mainly involving possession, production, and supply of controlled drugs. Moreover, Section 28 (3) (a) specifically provides that mere ignorance on the part of an accused that the substance in question was the particular controlled drug alleged shall not be a defence-the opposite, in other words, of what your correspondent states. Such ignorance shall be a defence (Section 28 (3) (b) (i) and (ii)) only if the accused believed the substance in question was not a controlled drug at all or else believed it to be a controlled drug such that, if it had been that drug, there would have been no offence involved.

My second comment concerns your correspondent's statement that, when circumstances are such that an early prohibition of a practitioner from any dealing with controlled drugs is required, the Minister is empowered to give a temporary direction (prohibiting the practitioner from prescrib ing, etc.). This rather suggests, especially in view of what has gone before, that the de cision is entirely within the Minister's pro vince. In fact, Section 15 lays down that, where the Minister proposes to give such a direction, he must refer the case to a professional panel and receive its agreement before giving the direction; and having given it, must forthwith refer the matter to a tribunal for review, four of the tribunal's five members to be of the respondent's profession.-I am, etc.

\section{How Caple,
Hereford}

S. BRADSHAW

** We regret that a transcribing error led to misquotation of Section 28 of the Act. This should have read "if he proves that he neither believed nor suspected ...'We agree with Dr. Bradshaw's comments. ED., B.M.F.

\section{Responsibility of the Scientist}

SIR,-Sir George Pickering (16 October, p. 131) takes pains to deny that Thomson, Rutherford, and Bohr can be held responsible for the horrors of Hiroshima and Nagasaki. Says he: "I have little doubt that Thomson, Rutherford, and Bohr, did not dream that their discoveries would give man the means to destroy himself."

At first the purpose of this denial might not be very clear, because no one has recently accused them of direct involvement in these crimes against humanity. Thereafter, Sir George proceeds to lay the blame for these crimes, the threat of future nuclear holocausts, and all the ills resulting from the activities of scientists on the "community," thus kindly enabling housewives, farmers, bus conductors, cab drivers, and such lesser mortals to share the burden among themselves in a democratic manner. I quote again: "I find it truly remarkable that apparently sensible people should blame science for what is the community's failure to use scientific knowledge to social ends It was not the knowledge of what atomic fission would do, but the decision to use that knowledge to destroy human beings that was decisive."

From the foregoing I conclude that he has chosen to employ techniques rather commonly used by those who wish to absolve "scientists" of all blame for the blunders that threaten life on this planet. First, one denies, on fairly good grounds, that some well-known scientists were responsible for these blunders. (This presumably exonerates the rest of the priesthood also.) Then one proceeds to subtly bring in the word "community" or "mankind" instead of "scientists."

Let not this verbal sleight of hand obscure our vision of some facts. Is it not true that some scientists coldly and deliberately used the principle of nuclear fission and fashioned bombs of horrible destructive power out of it? Surely the plans for these germinated, grew, and came to fruition in the minds of some scientistsnot in the minds of the "community" consisting of lesser mortals listed above? If the "decision to use that knowledge to destroy human beings" is culpable, surely so are the "scientists" who made this decision? Or does anyone think that the "decision" came from the "community"? I should think that scientists are much more likely to have formulated the idea in their brains.

If the names of these "scientists" are less well known than those of Thomson, Rutherford, and Bohr, the reasons for this lack of popularity are easy to work out. It is partly because the names are probably concealed in secret government files, either for security reasons or to facilitate these "scientists" to hide their guilt and shame. Another likely reason appears to be that solicitous fellow scientists help by not exposing them when possible, but resort to inviting the "community" to take the rap.

It is perfectly obvious that science can neither be good nor bad. It should be equally clear that such a qualitative assessment is possible of the actions and inventions of scientists. An invention can be useful, useless, or horribly destructive. When making these self-evident points, one is often accused of flogging dead horses. That the horses are not as dead as is commonly thought is suggested by the failure of scientists, writing in 1971, to appreciate that chaps who use scientific knowledge for inventing things should be consistently called "scientists." What I find truly remarkable is that "scientists," when they speak in public or write, use this honorific title to praise the discoverer of penicillin, but mysteriously fail to refer to those who made the atom bomb as "scientists." They are cloaked in the comfortable anonymity of "the community," or sometimes "mankind." For example, Sir George intuitively and rightly lauds the "good" scientist Bohr's futile attempts to stop atomic bombs being made, but curiously, he fails to condemn the "bad" scientists-oops! sorry, "community"-who went ahead and made them, anyway.

To the question "How can one predict which inventions of scientists will turn out to be useful and which disastrous?" the reply has to be, unfortunately, another question. Namely, "How can one set about solving this problem when the high priests are unwilling to admit that some of their actions have been, and will surely turn out to be, disastrous?"

Why, oh why cannot a "scientist" (their prime passion is presumably for accuracy!) have the courage to say: "Some scientists 